\title{
PRÁTICAS DE ESCRITA DE EDUCADORAS COMO EXPERIÊNCIA FORMATIVA NA ESCOLA
}

\author{
WRITING PRACTICES OF EDUCATORS AS A FORMATIVE \\ EXPERIENCE IN THE SCHOOL
}

\author{
PRÁCTICAS DE ESCRITA DE EDUCADORAS COMO \\ UNA EXPERIENCIA FORMATIVA EN LA ESCUELA
}

\author{
Keila Santos Pinto ${ }^{\mathrm{I}}$ \\ Laura Noemi Chaluh ${ }^{\mathrm{I}}$
}

REsumo Este trabalho apresenta parte de uma pesquisa de mestrado que buscou compreender a atuação da professora coordenadora, no contexto dos espaços de formação na escola, por meio das práticas de escrita realizadas pelas professoras e professora coordenadora em uma escola municipal de Educação Infantil, localizada no interior do Estado de São Paulo. O percurso investigativo da pesquisa pautou-se na narrativa de experiências do vivido (LIMA, GERALDI E GERALDI, 2015), e os dados foram analisados a partir do paradigma indiciário de Ginzburg (1989). Como professora coordenadora, ao pesquisar sua própria prática, a intenção foi mobilizar uma experiência formativa, que ampliasse a interlocução entre as educadoras, exercício esse que disparou a reflexão a respeito das potencialidades e das limitações das práticas formativas existentes na escola, ao legitimar a escola como espaço-tempo de produção de sentidos e conhecimentos. Uma das propostas dessa interlocução foi o Diário de HTPC (Horas de Trabalho Pedagógico Coletivo), uma ação coletiva de escrita que possibilitou propor diferentes formas de organização desse espaço de formação, ao promover o movimento das palavras, a liberdade de dizer sobre si e acerca do outro, o estreitamento das relações de intimidade e confiança e o compartilhamento dos sentimentos e saberes.

Palavras-chave: Professor Coordenador; Formação Continuada; Escola; Narrativas.

I Universidade Estadual Paulista "Julio de Mesquita Filho" (UNESP) Rio Claro/SP - Brasil 
Abstract This paper presents part of a master's research that sought to understand the performance of the coordinator teacher, in the context of formation in the school, through the writing practices performed by the teachers and the coordinator teacher in a public preschool, located at São Paulo state. The investigative path of the research was based on the narrative of "lived experiences" (LIMA, GERALDI and GERALDI, 2015), and the data was analyzed from Ginzburg's indiciary paradigm (1989). As a coordinator teacher, researching your own practice, the intention was to mobilize a formative experience, which enhanced the interlocution between educators, an exercise that triggered reflection on the potentialities and limitations of the existing formative practices in the school, by legitimizing the school as "space-time" of knowledge and meaning production. One of the proposals of this interlocution was the HTPC (Collective Pedagogical Work Hours) diary, a collective action of writing that made possible to propose different forms of organization of this formation space, when promoting the movement of the words, the freedom to speak about yourself and about the other, the strengthening of the intimacy and trust relationships and the sharing of feelings and knowledge.

Key-words: Coordinator Teacher; Continued Education; School; Narratives.

Resumen Este trabajo presenta la parte de investigación de una maestría que buscó comprender la actuación de la profesora coordinadora, en el contexto de los espacios de formación en la escuela, por medio de las prácticas de escrita realizadas por las profesoras y la profesora coordinadora en una escuela municipal de Educación Infantil, localizada en el interior del Estado de San Pablo. El camino de la investigación se pautó en la narrativa de experiencias de lo vivido (LIMA, GERALDI E GERALDI, 2015), y los datos fueron analizados a partir del paradigma indiciario de Ginzburg (1989). Como profesora coordinadora que investigó su propia práctica, la investigadora buscó movilizar una experiencia formativa, que ampliase la interlocución entras las educadoras, ejercicio que disparó la reflexión sobre las potencialidades y limitaciones de las prácticas formativas existentes en la escuela, al legitimar la escuela como espacio-tiempo de producción de sentidos y conocimientos. Una de las propuestas da interlocución fue el Diario de HTPC (Horas de Trabajo Pedagógico Colectivo), una acción colectiva de escrita que posibilitó proponer diferentes formas de organización de ese espacio de formación, al promover el movimiento de las palabras, la libertad de decir sobre sí y sobre el otro, el estrechamiento de las relaciones de intimidad y confianza y el compartir los sentimientos y saberes.

Palabras clave: Profesor Coordinador; Formación Continuada; Escuela; Narrativas.

\section{INTRODUÇÃo}

Este trabalho é um recorte da pesquisa de mestrado que investigou, durante o ano de 2014, a atuação da professora coordenadora, primeira autora do presente trabalho, como formadora na escola, ao buscar compreender as relações estabelecidas nos espaços de formação

68 Comunicações | Piracicaba | v. 24 | n. 3 | p. 67-83 | setembro-dezembro 2017 
continuada na escola. Durante esse processo formativo, professoras e professora coordenadora apropriaram-se das práticas de escritas como modo de intensificar a interlocução. A pesquisa foi desenvolvida em uma escola municipal de Educação Infantil, Etapa $I,{ }^{1}$ que atende crianças de quatro meses a 3 anos de idade, localizada no interior do Estado de São Paulo.

A proposta de intensificar a prática de escrita na escola surgiu do desejo da professora coordenadora, de aproximar-se das educadoras ${ }^{2}$ (monitoras e professoras) e de mobilizar situações de escritas para além daquelas já instituídas na escola, como os planejamentos, planos de trabalho e diário de bordo, e assim incentivar as educadoras a escreverem mais, ao narrarem sentimentos e percepções acerca de si e da escola.

Esse desejo da professora coordenadora foi revelado em um dos encontros do curso de extensão "Escola: espaço de formação de professores", realizado em 2013 na UNESP, Campus de Rio Claro, coordenado pela segunda autora deste trabalho. O curso foi oferecido a coordenadores pedagógicos, ${ }^{3}$ professores coordenadores, ${ }^{4}$ vice-diretores da rede municipal de ensino e alunas do Curso de Licenciatura Plena em Pedagogia da referida universidade. Esses encontros eram mensais, e as participantes do curso foram constantemente desafiadas a se movimentar em prol dos seus desejos e necessidades de tal forma que contribuíssem com a formação das educadoras na escola, ao mobilizarem a crença que é possível fazer uma escola outra e ao reconhecerem e legitimarem a escola como espaço de produção de saberes e conhecimentos.

Portanto, em um dos encontros do curso, após diálogo com o grupo, a professora coordenadora relatou que suas devolutivas às educadoras da escola sobre o trabalho que realizavam eram, na sua maioria, orais, eram escassas as escritas tanto da professora coordenadora, como das educadoras. Então foi sugerido pela coordenadora do curso que a professora coordenadora escrevesse às educadoras, sendo que a primeira escrita foi uma carta, e a partir dessa carta disparou-se na escola o movimento de escrita. A carta foi escrita à mão e reproduzida cópias que foram entregues às educadoras (monitoras e professoras), dando uma devolutiva do primeiro semestre letivo do ano de 2013.

1 Etapa I refere-se à primeira etapa da Educação Infantil, a qual atende a crianças de até 3 anos de idade, que são organizadas nas turmas de: Berçário I, Berçário II, Maternal I e Maternal II. Na escola onde foi realizada a pesquisa, as crianças são atendidas em período integral, das $7 \mathrm{~h}$ até as $17 \mathrm{~h}$, em duas salas de Berçário I com 12 bebês em cada turma; três salas de Berçário II com 16 crianças em cada turma; e três salas de Maternal I com 20 crianças em cada turma, totalizando oito salas e 132 crianças.

2 Nas escolas de Educação Infantil, Etapa I, trabalham monitoras e professoras, sendo que nas salas dos Berçários I e II trabalham somente as monitoras, e nas salas de Maternal I as monitoras trabalham em período integral e as professoras, junto às monitoras, trabalham no período da manhã. A partir de 2015, no município, as monitoras passaram a ser nomeadas de agentes educacionais.

3 Profissional da educação (professor ou diretor) que afastado do seu cargo, exerce uma função de confiança de suporte pedagógico junto à Secretaria Municipal de Educação, e é o responsável por coordenar e acompanhar os trabalhos dos professores coordenadores e professores da rede municipal de ensino.

4 Professor efetivo eleito pela Equipe Docente e Gestora que, afastado do seu cargo, exerce a função de professor-coordenador na escola, desenvolvendo as seguintes ações: coordenar, acompanhar e avaliar o processo pedagógico no âmbito da Unidade Educacional. 
Essa carta foi respondida pela maioria das educadoras, oportunizando reflexões à professora coordenadora e apontando caminhos pelos quais ela poderia seguir para reorganizar o seu trabalho na escola. É importante destacar o quanto as educadoras se sentiram valorizadas ao receber e ler a carta, e o quanto elas se mostraram entusiasmadas ao respondê-la. A partir desse momento de escritas das cartas, outras escritas começaram a ser realizadas na escola, ampliando-se a interlocução entre as educadoras.

Assim, ao longo dos anos 2014 a 2016, e com o ingresso da referida professora coordenadora no mestrado em 2014, ela se dispôs a pesquisar a sua própria prática, por meio da narrativa de experiência do vivido, ao investigar suas ações de formação na escola, a partir das práticas de escrita. Assim, este trabalho socializa uma das práticas de escrita constituída a partir das Horas de Trabalho Pedagógico Coletivo (HTPC's), o Diário de HTPC, uma escrita coletiva realizada em um livro ata, nas quais participaram quatro professoras: $\mathrm{Si}$, Van, Vivi e Zeza ${ }^{5}$ para mostrar parte das ações de formação desenvolvidas na referida escola.

\section{Pesquisa narRativa: inVestigaÇão e Compreensão do Vivido}

A investigação foi realizada a partir dos pressupostos da narrativa de experiências do vivido (LIMA; GERALDI; GERALDI, 2015), a qual propõe ao pesquisador lançar-se a interrogar o vivido, aproximando-se das histórias de vida dos educadores e da sua própria história e valorizando os conhecimentos e saberes produzidos na escola. Ao pautar-se nessa proposta de pesquisa narrativa, foi possível à pesquisadora (professora coordenadora) pesquisar a sua própria prática na e com a escola (CHALUH, 2008, 2011), com ela e a partir dela (LIMA; GERALDI; GERALDI, 2015), de tal forma que o conhecimento e saberes produzidos neste contexto fossem compartilhados por meio das experiências vividas.

Experiências vividas que são apresentadas após uma investigação atravessada por incertezas, escolhas e aprendizagens, na busca por uma compreensão significativa, a qual não se fundamenta em uma verdade única, mas propõe vasculhar os pormenores, as brechas, os escapes presentes no cotidiano. Segundo Ginzburg (1989, p. 144), “é preciso não se basear, como normalmente se faz, em características mais vistosas [...] é necessário examinar os pormenores mais negligenciáveis".

A pesquisa narrativa possibilita experienciar a vida com o olhar atento, ao buscar nos dados irrelevantes a relevância, nas desimportâncias as importâncias (BARROS, 2008). Assim, investigar na e com a escola é acercar-se da produção de sentidos em um espaço micro atravessado por histórias múltiplas, mas singulares, as quais revelam concepções de determinado tempo e espaço, contribuindo para a compreensão dos modos de ser e fazer escola. A escola como lugar praticado, de aproximação e reconhecimento, capaz de provocar o encontro polifônico e enunciar lições e aprendizagens.

Nessa perspectiva, a partir dos pressupostos de Benjamin (1994), a narrativa convida a pesquisadora a revelar suas experiências a partir dos acontecimentos vividos com os

5 Os nomes das professoras são apelidos ou abreviaturas de seus nomes, dessa forma elas eram chamadas e conhecidas na escola, para a pesquisa elas consentiram esse uso e não o nome fictício.

70 Comunicações | Piracicaba | v. 24 | n. 3 | p. 67-83 | setembro-dezembro 2017 
sujeitos $n a$ e $d a$ escola e a tirar lições por meio das experiências vividas, lições que são os "sentidos produzidos pela pesquisadora com base no encontro com os seus outros" (CHALUH, 2008, p. 260, grifo da autora).

A pesquisa narrativa não meramente informa a experiência, mas oportuniza ao outro, segundo Dutra (2002), ouvir a história e a transformar de acordo com a sua interpretação, levando a experiência a uma maior amplitude, como acontece na narrativa que, diferentemente da informação, não nos dá respostas. Ao contrário, a experiência vivida e narrada sensibiliza, alcança-nos a partir dos significados que atribuímos a ela, quando nos deixamos "afetar pelas circunstâncias e pelo contexto em que a cena da pesquisa se desenrola" (JOBIM e SOUZA; ALBUQUERQUE, 2012, p. 113).

Essa investigação permite a construção de um conhecimento local, o qual, para Santos (2010), é útil aos indivíduos de determinada comunidade, sem ser determinístico. $\mathrm{Na}$ escola, a pesquisa:

[...] não pode se restringir a mero retrato do que se passa no seu cotidiano, mas deve envolver um processo de reconstrução dessa prática, desvelando suas múltiplas dimensões, refazendo seu movimento, apontando suas contradições, recuperando a força viva que nela está presente (ANDRÉ, 2010, p. 16).

As narrativas de experiências do vivido ocupam esse espaço de interlocução e remetem à indissociabilidade entre pesquisa e formação, ao provocar ações que movimentam e reconstroem as práticas cotidianas na escola. Ao dialogar com Bakhtin (2003), depreendeu-se que a pesquisa narrativa só pode se dar na dimensão do encontro, ao ser compreendida por meio da alteridade, da interlocução, do estranhamento e do excedente de visão.

Ao realizar a pesquisa percebeu-se que a narrativa provocou muitas indagações, pois o caminho das narrativas é o da interrogação e não o da resposta única e verdadeira. Dessa forma, estenderemos as discussões, ampliando as possibilidades de reflexão e criação, ao elucidar parte da experiência formativa vivenciada pela pesquisadora, por meio do exercício da escrita no Diário de HTPC.

\section{DiÁRIO DE HTPC: EXPERIÊNCIA FORMATIVA E AMPLIAÇÃO DA INTERLOCUÇÃo}

Nos espaços de formação instituídos na escola - HTPC's e Horas de Trabalho Pedagógico Individual (HTPI's) - foram realizadas propostas de escritas que auxiliaram o trabalho da professora coordenadora. Nesses espaços de formação, para além das leituras e discussões de textos teóricos e literários, as educadoras foram convidadas a registrarem suas impressões acerca desses encontros, assim, tal proposta permeou os registros reflexivos, a narração de si através de memoriais e o Diário de HTPC.

O Diário de HTPC constituiu-se em um registro coletivo que trouxe para nós a dimensão dos encontros de formação nas HTPC's, ao apresentar os sentidos produzidos nesse espaço, de forma a contribuir com a nossa prática na escola. Segue a escrita da professora coordenadora revelando a intenção de propor essa escrita: 
Nesse ano de 2014 continuarei o trabalho com as escritas, não somente as cartas. Acredito que propiciar ao outro esse momento de escrita trará possibilidades de reflexão e estruturação do meu trabalho.

Tenho pensado quais escritas que utilizarei ao longo do ano com as educadoras, pretendo oferecer o uso de um diário para o registro após HTPC, para que as professoras possam colocar suas sensações e sentimentos em relação ao encontro. Eu já estava pensando em utilizar alguns tipos de registros das professoras nos momentos de formação HTPC e HTPI principalmente, após conversa com a professora orientadora essa vontade se intensificou, e no segundo encontro de HTPC uma das professoras falou o quanto tinha gostado daquele encontro, e que esse momento a tinha ajudado a pensar algumas coisas em relação ao trabalho com as crianças, achei importante esse compartilhamento que poderá ser feito, se as professoras aceitarem a realização desse registro, a proposta é que cada encontro uma das professoras leve o caderno para casa para colocar suas impressões da HTPC. Tomara que elas topem! (DIÁRIO DE PC, 07-02-2014).

$\mathrm{Na}$ primeira HTPC do ano foi solicitado às professoras que fizessem um registro acerca das suas expectativas para o ano e que escrevessem suas impressões a respeito dos encontros de formação na escola. Dando continuidade a esse processo, a proposta do Diário surgiu quando a professora coordenadora percebeu que as professoras poderiam contribuir com esses espaços ao explicitarem seus olhares.

Naquela primeira HTPC do ano de 2014, uma das professoras havia comentado com outra professora, a qual esteve ausente, o quanto tinha gostado daquele encontro, que lhe auxiliou a pensar sobre o trabalho que poderia ser desenvolvido com as crianças e a importância desses espaços de formação na escola. Nesse momento, a professora coordenadora ampliou a sua percepção acerca da potência daqueles encontros, atentando-se para o pressuposto que as professoras tinham muito a lhe dizer e era necessário mobilizar essa interlocução.

Assim, foi proposto o registro dos encontros das HTPC's em um livro ata, diferente do já existente, já que a professora coordenadora tem a responsabilidade de registrar os encontros de uma maneira formal no livro ata específico. As educadoras aceitaram a proposição e a Van deu a sugestão de ser o Diário de HTPC, fazendo relação ao filme "Diário de uma paixão", 6 e Vivi dando continuidade ao pensamento da Van lembrou-se do filme "Escritores da liberdade". ${ }^{7}$ Segue o primeiro registro da professora coordenadora no Diário de HTPC:

Esse será o nosso diário de HTPC, o nome foi proposto pela professora Van, e todas aceitaram. Primeiramente a professora coordenadora propôs às professoras a ideia de realizar o registro do HTPC nesse livro ata, sendo que a cada encontro uma professora ficará responsável por registrar suas impressões sobre

6 Filme norte-americano, de 2004, dirigido por Nick Cassavete e ancorado no livro de mesmo nome de Nicholas Sparks. No filme, um idoso narra a história de um jovem casal da década de 1940.

7 Filme de drama norte-americano lançado em 2007. Dirigido por Richard LaGravenese e produzido por Danny DeVito, Michael Shamberg e Stacey Sher, o filme é inspirado nos eventos reais relatados no livro The Freedom Writers Diaries, ancorado nos relatos da professora Erin Gruwell e seus diversos alunos, abordando de maneira comovente os desafios da educação em uma sociedade desigual. 
os encontros, podendo através do registro: colocar sugestões, opiniões e expor seus sentimentos.

A professora levará o livro para casa, fará o seu registro e trará no próximo encontro, podendo no início do encontro compartilhar seu registro com as demais colegas.

A escrita poderá ser realizada de diferentes maneiras, podendo se utilizar de diferentes gêneros textuais.

Essa proposta de registro surgiu após alguns acontecimentos: primeiro porque uma das professoras trouxe apontamentos relevantes sobre um encontro que tivemos, e ocorreu a professora coordenadora a necessidade de registrar tais impressões para que nos dessem subsídios para estruturar os próximos encontros, importando-se principalmente com as necessidades das professoras, assim é importante que vocês se manifestem, tenham vozes e possam falar de si, da sua profissão, da escola, e dos encontros de formação, como a HTPC.

Nos encontros de HTPC há uma ata, mas essa é realizada pela professora coordenadora, assim esse diário terá outro objetivo, não só de registrar, mas também considerar os interesses e as impressões das professoras. Esse exercicio da escrita é muito importante para o processo de formação. Principalmente porque as professoras podem refletir sobre os encontros, colocar suas ideias e sentir-se participante nesse processo.

Para mim, professora coordenadora, esse diário é visto como possibilidade de ampliação do meu trabalho e aproximação das professoras, um instrumento de comunicação e orientação. Estou muito feliz, porque as professoras aceitaram essa proposta, e acredito que o diário nos trará muitas contribuições (PC, ${ }^{8}$ DIÁRIO DE HTPC, 07-04-2014).

Nas palavras eternizadas no Diário de HTPC foram reveladas as impressões dos encontros a partir de um olhar singular, pois cada semana uma de nós levava o diário para casa, mas ao partilhar os registros houve os desdobramentos de olhares que dispararam uma compreensão coletiva e a apresentação dos pontos de vista das professoras e da professora coordenadora. Por meio desse movimento, a professora coordenadora aproximou-se das professoras e, como formadora na escola, começou a organizar esses espaços a partir das impressões e necessidades do grupo.

O registro no Diário apresentou-se de tal forma, ao provocar a professora coordenadora a refletir sobre a organização desse espaço de formação, pois diante do olhar e da perspectiva das professoras, ela teve a possibilidade de ser tocada por aquele que estava em outro lugar, e por isso "consegue enxergar coisas a meu respeito que eu mesma não consigo enxergar” (CHALUH, 2008, p. 192).

Para compreender a grandeza desses encontros, segue parte do registro no Diário de HTPC feito pela Van:

Iniciamos nossa reunião conversando um pouco sobre o dia, as escolas e com o lanchinho. Esse momento é muito bom, além de descontração, podemos desabafar, rir e até mesmo trocar ideias [...].

$8 \quad$ PC refere-se à professora coordenadora e pesquisadora. 
[...] Nos reunimos na mesa (as professoras) para expor as angústias, as coisas boas, as melhorias que vieram e podem vir, enfim, conversamos sobre a realidade de cada escola.

Também, rimos no final, num momento de descontração. Foi muito legal! Bom diário, até a próxima! (Van, DIÁRIO DE HTPC, 14-04-2014).

A dimensão da grandeza dada a esses encontros semanais refere-se aos sentimentos da professora coordenadora, pois no final do dia com o cansaço aparente, esse espaço tinha o poder de revigorá-la, já que a participação das professoras começou a se mostrar com maior intensidade, e realmente aquele espaço estava constituindo-se de formação. Primeiro pela acolhida, preparávamos um lanche para as educadoras, e esse momento inicial era disparador, como explicita Van. Segundo, quando sentávamos em roda era um momento múltiplo de construções, que era tenso quando se falava das angústias e frustrações, mas também de descontração, tendo lugar o riso e as trocas, quando todas se sentem autorizadas a sugerir ideias e a falar sobre si e o outro.

No registro de Si, ela também apresenta esse momento como de trocas de experiências, ideias e opiniões:

Trocamos ideias e experiências, conversamos sobre a importância da postura da professora diante da criança, como por exemplo: sentar junto na roda de conversa, procurar sempre envolver a criança com o olhar, participar das brincadeiras, etc.

Acho muito proveitoso as HTPC's em que interagimos e trocamos experiências, onde expomos nossas opiniões e ouvimos opiniões das outras professoras ( $\mathrm{Si}$, DIÁRIO DE HTPC, 02-06-2014).

As HTPC's pautaram-se nas expectativas, necessidades e saberes das professoras, ao mobilizá-las para as trocas de experiências e diálogos sobre o seu cotidiano, suas concepções e ações, ao permitir interrogar os desafios vivenciados na escola. Ao considerar Cunha e Prado (2010, p. 102), foi proposto um processo formativo "no contexto de trabalho, privilegiando a colaboração, a interlocução sobre as práticas, as necessidades e os interesses dos professores que participam da construção e da gestão do plano de formação e são corresponsáveis pelo seu desenvolvimento".

Um processo exercido na vivência e na dimensão do encontro, do diálogo inserido no dinamismo de alteridade e na prática cotidiana (FURLANETTO, 2000), a partir das interações entre os sujeitos que se constituem e se identificam por intermédio do outro, identificação visível quando as percepções e os anseios das educadoras revelados no diário eram convergentes.

A leitura do diário apresentou à professora coordenadora modos de organização do seu trabalho, por exemplo, quando a professora Van aponta que a leitura dos textos era como diálogos, uma estratégia de leitura da professora coordenadora que instigava a interferência das educadoras, provocando diálogos tanto com o texto, como entre as professoras, algo que a professora coordenadora só percebeu após o apontamento de Van no diário: 
Conversamos bastante, fizemos a leitura com diálogos sobre o tema, qual educação queremos para os nossos alunos e nosso papel como educador [...]

[...] Foi um momento muito proveitoso e nós, conversando sobre os dilemas e alegria do ato de ensinar (Van, DIÁRIO DE HTPC, 09-02-2014).

Ao almejar um espaço de formação dialógico, durante o ano a professora coordenadora vivenciou um dilema referente a um encontro de HTPC que foi organizado pela professora coordenadora de outra escola, já que alguns encontros eram realizados junto a várias escolas de Educação Infantil. Naquele encontro, aquela professora coordenadora mostrou uma proposta de trabalho que as professoras já conheciam, e algumas já realizavam, mas o modo como ela apresentou não permitiu que as professoras falassem sobre suas experiências, para haver trocas, seu posicionamento diante das professoras desconsiderou os seus saberes e conhecimentos. Segue parte do registro da professora Vivi no Diário de HTPC acerca desse encontro:

Ocorreu uma argumentação insistente de que a proposta poderia ser complicada, mas era possivel o que na minha interpretação configurou-se por nivelamento por baixo, ou seja, ignorou-se nossas experiências, nosso conhecimento empírico e até mesmo acadêmico (Vivi, DIÁRIO DE HTPC,16-06-2014).

Essa experiência possibilitou algumas aprendizagens, pois revelou a necessidade de levar em consideração os saberes construídos pelas professoras, o que implica outra concepção de formação que não é de cima para baixo, e sim uma formação sustentada no reconhecimento do outro e no diálogo.

Pois, segundo Nóvoa (2011, p. 15), é imprescindível uma formação que não reduza o professor a "um conjunto de competências e de capacidades, realçando essencialmente a dimensão técnica da ação pedagógica", uma concepção escolarizada da formação de professores, na qual não há espaço para a partilha das experiências, dos saberes e conhecimentos, disseminando o esvaziamento da ação pedagógica, apontada por Geraldi $(2004,2010)$ como a ausência da possibilidade do professor produzir seus saberes, ao ser considerado mero executor. Para o referido autor, os professores na escola precisam perceber que são capazes de produzir conhecimentos a partir de suas experiências cotidianas confrontadas com seus saberes, dessa forma, eles não estarão somente reproduzindo o conhecimento produzido por outros, mas estarão em constante processo de interrogação do vivido.

Assim, a formação que não considere tais premissas de produção do conhecimento apropria-se das políticas de formação pelo tempo zero (COLLARES; MOYSÉS; GERALDI, 1999), ao buscar a qualificação dos profissionais da educação desconsiderando sua história, experiências e saberes, ao determinar a escola apenas como espaço de transmissão de conhecimento. Nessa perspectiva, a educação continuada que "mantém a separação entre produção e utilização de conhecimentos, entre sujeitos e conhecimentos, não só desvaloriza os saberes, mas também os sujeitos que os produzem" (p. 210).

No registro da professora podemos observar o quanto ela se sentiu desvalorizada com a proposta de formação que foi vista como transmissão e acumulação de conheci- 
mentos, sem preocupar-se em vincular suas experiências e saberes, dimensões essas que imprimem sentidos ao fazer educativo.

É importante destacar que a professora coordenadora também fazia os seus registros nesse diário, seus sentimentos também foram revelados ao grupo, um exemplo foi o registro após a HTPC na qual foi realizada a dinâmica do Jornal de Parede, ${ }^{9}$ como momento avaliativo do trabalho pedagógico na escola, a partir dos enunciados: eu critico, eu proponho, eu felicito.

\begin{abstract}
[...] iniciamos com o "Eu critico...", esse momento é bem dificil, pois ouvimos coisas, críticas, que não gostaríamos, normalmente são os mesmos problemas, questões difíceis de serem solucionadas, pois também depende do outro, assim conversamos sobre a função social da escola e de seus educadores, principalmente ao que se refere à relação com o outro - colega de trabalho elou educandos, e suas responsabilidades, às vezes, surge o sentimento de impossibilidade, inutilidade e incapacidade por não dar conta de algumas situações, mas aos poucos, reavivamos nosso compromisso, e pensamos sobre as melhores ações para alguns "problemas" ou práticas mudem [...]

Esses momentos são importantes para repensarmos sobre nossa responsabilidade e compromisso, e permite que todos possam expor suas opiniões e a partir delas podemos dialogar. Eu saí bem angustiada desse encontro, em conflito, mas acredito que logo o equilibrio se estabeleça. "Estou tentando fazer o melhor" (PC, DIÁRIO DE HTPC, 07-07-2014).
\end{abstract}

Muitos sentimentos permearam esse encontro, quando a professora coordenadora se lançou a dialogar acerca de algumas questões desafiadoras e conflitantes no cotidiano escolar, ela se expôs como responsável por minimizá-los, porém em alguns momentos sentia-se cansada e angustiada, pois de imediato não conseguia dar conta de determinadas situações, mas aos poucos, por meio de pequenos movimentos, reconstruía-se, buscando modos de pensar e fazer junto às educadoras.

No geral, foram vivenciadas mais situações prazerosas, pois como a professora coordenadora aponta em outro registro no diário, os encontros de formação trouxeram as experiências do vivido, desvelando as concepções inerentes ao trabalho do educador e a devolutiva do movimento constituído nesse espaço significativo de formação. Segue parte do seu registro:

Interessante para mim foi perceber as trocas de experiências e a reflexão sobre algumas ações já vistas ou realizadas, o que proporcionou a conversa sobre a postura do educador e a nossas concepções sobre a educação, principalmente ao que se refere à relação que se estabelece com as crianças.

9 O jornal de parede é uma das técnicas utilizadas pela pedagogia Freinet (1998) que prioriza a organização cooperativa, considerando a escola um espaço de diálogo, escolhas e compartilhamento de conhecimentos. O artigo "O jornal de parede e o exercício da cidadania", de Heloísa F. Zago e Tânia Laudani, publicado no livro "Palavras de professor (a): tateios e reflexões na prática da pedagogia Freinet", organizado por Gláucia de Melo Ferreira apresenta a experiência das professoras com essa prática.

76 Comunicações | Piracicaba | v. 24 | n. 3 | p. 67-83 | setembro-dezembro 2017 
[...] fiquei feliz com a devolutiva, pois percebi que essas discussões que auxiliam o trabalho junto com as crianças estão sendo significativas e está sendo posto em prática. Vejo a construção de um trabalho coletivo, possibilitador da ampliação do saber docente (PC, DIÁRIO DE HTPC, 01-10-2014).

O movimento de enunciar as palavras, por meio das escritas no Diário de HTPC, permitiu que as educadoras falassem e fossem ouvidas e, como explicitado, essa interlocução não esteve atrelada somente às situações prazerosas, pois as palavras registradas no diário traziam elogios, críticas, sabores e dissabores do nosso cotidiano. E foi esse movimento que orientou o trabalho de formação na escola e as práticas de acompanhamento do trabalho pedagógico, emergindo assim as escritas como experiência formativa.

Após um período, as escritas das professoras e da professora coordenadora no diário tornaram-se mais extensas e reflexivas e apresentavam um olhar delas sobre si, sobre os espaços de HTPC, sobre o trabalho da professora coordenadora. Assim, as escritas revelaram-se espaços de investigação e comunicação com múltiplas possibilidades de organização e aprendizagem na escola.

Uma proposta de formação que atribuiu sentidos e encontros, encontro consigo mesma e com o outro, ao valorizar as palavras do outro e as próprias palavras e ao auxiliar na compreensão da atividade docente.

\section{ESCRITAS: DIMENSÃO DIALÓGICA, REFLEXIVA E FORMATIVA}

A partir da prática da escrita, foi possível vivenciar uma experiência formativa, pois as escritas constituíram-se significativas ao comunicar algo de si próprio e da própria realidade. Ao oportunizar a interlocução, por meio de uma dimensão dialógica e reflexiva, as palavras transcreveram a singularidade, construindo a alteridade ao evidenciar as nossas concepções, crenças, inquietações e satisfações.

De acordo com Prado e Cunha (2006), a prática da escrita organiza e articula o pensamento, estimula a reflexão e incita para uma crescente fundamentação teórica, pois se busca alternativas para avançar e melhorar, o que permite a interrogação do real que mobiliza o diálogo entre teoria e prática e nos resgata como sujeitos-escritores.

As escritas favoreceram a construção das trajetórias de vida das professoras e da professora coordenadora, ao ancorar os modos de organização dos seus trabalhos, possibilitando o desenvolvimento profissional e pessoal, ao revelar-se como uma prática que permite evocar a memória, os pensamentos, a reflexão e a sistematização das ideias e dos saberes, o ensejo de dizer o que sentimos e pensamos. Revelando momentos de aproximação, intimidade e de fortalecimento de vínculos, a partir da oportunidade de

[...] dizer o que realmente sentimos e pensamos, por as cartas na mesa, buscar relações mais transparentes, proporcionam grande amadurecimento. Contatar seus sentimentos menos valorizados, seus lados mais sombrios e aprender a vê-los desvelados pelo outro não é tarefa fácil, mas um exercício que, feita de maneira cuidadosa, permite crescimento, fortalecimento de vínculos (FURLANETTO, 2000, p. 97). 
Por meio desse envolvimento mútuo ocasionado pela aproximação do outro, fomos conduzidas a pensar acerca das relações que estabelecemos com o outro e com o ambiente educacional. Dessa forma, corresponder-se com o outro é expor a si mesmo e olhar para o outro através do olhar de si, "como auto escuta, como se estivesse contando para si próprio suas experiências e aprendizagens" (SOUZA, 2006, p. 14).

Collares, Moysés e Geraldi (1999) apontam que o essencial das narrativas de experiências está no fato de os sujeitos se assumirem como enunciadores, estabelecendo uma relação de construção de interpretações e compreensões sobre o que lhes acontece.

As escritas sobre a experiência vivida mostram-se como instrumento de aprendizagem, e segundo Prado e Cunha (2006, p. 112):

O professor que escreve sobre a experiência vivida, sobre a prática profissional,
as dúvidas e os dilemas enfrentados, sobre o processo pessoal de aprendizagem
exige, ao mesmo tempo, tematizar a prática - torná-la objeto de reflexão - e
documentar essa reflexão por escrito [...]. Porque a reflexão por escrito é um
dos mais valiosos instrumentos para aprender sobre quem somos nós - pessoal
e profissionalmente - e sobre a nossa atuação como educadores, uma vez que
favorece a análise do trabalho realizado e do processo de aprendizagem, o de-
senvolvimento da capacidade de escrever, a sistematização dos saberes adquiri-
dos, o uso da escrita como ferramenta para o crescimento profissional.

As escritas tornaram-se eixo mediador entre as professoras e a professora coordenadora, possibilitando o compartilhamento das experiências, sobre os modos como nos colocamos na escola e no mundo, e nos relacionamos conosco e com os outros, um processo dialógico e formativo. Pois, como considerado por Pierini e Sadalla (2008, p. 81):

Bom é registrar para expressar, para tomar nas mãos o que se revela de cada um e fazê-lo de todos, para materializar o revelado. Bom é registrar e trazer à tona fragmentos de momentos onde cada um se afirma ao afirmar suas verdades, onde cada um ouve as verdades do outro, melindra-se com elas, se incomoda, se inquieta, traz para o outro sua inquietação, fala, publica suas convicções, se revê ao rever o outro.

Nóvoa (2011) afirma que o registro das vivências pessoais e das práticas profissionais é essencial para adquirir-se uma maior consciência do trabalho e da identidade de professor, é assim um processo formativo que contribui ao criar nos professores hábitos de reflexão e de autorreflexão, algo essencial numa profissão que não se esgota em matrizes científicas ou mesmo pedagógicas, e que se define, inevitavelmente, a partir de referências pessoais. Referências pessoais que temos a partir do olhar do outro sobre nós, pela valorização do que somos e sabemos. Assim, a nossa constituição como educador é apreendida em um processo de alteridade, pois:

Somente em relação a outro indivíduo tornamo-nos capazes de perceber nossas características, de delinear nossas peculiaridades pessoais e nossas peculiari- 
dades como profissionais, de diferenciar nossos interesses das metas alheias e de formular julgamentos sobre nós próprios e sobre o nosso fazer (FONTANA, 2003, p. 62).

As escritas permitiram o conhecimento de si, por meio da emoção, da imaginação e da criação, dimensões essas tão ausentes nos espaços escolares, já que imersos em um tempo acelerado nos distanciamos de vivenciar experiências que produzem sentidos em nós e nos outros. Cada palavra lida das escritas das professoras suscitava desejos à professora coordenadora, que foram articulados à esperança de constituir com elas uma experiência formativa significativa.

Nesse processo, foi possível criar modos distintos de produção de saberes, pois a escrita como experiência é formação que, quando realizada em situações reais de comunicação, amplia os sentidos e a interação, possibilitando às educadoras que se posicionem, expressem suas opiniões e sentimentos, e se sintam autônomas, pertencentes ao grupo e responsáveis por ele. Pois, compreendemos

[...] o quão importante é oportunizar o exercício da voz, da escuta, da reflexão, da exposição, da coordenação, pautar a organização dos espaços de formação nos princípios de construção da autonomia dos profissionais da escola (PIERINI; SADALLA, 2008, p. 80).

Para Souza (2006), a escrita da narrativa abre espaços e oportuniza, aos professores em processo de formação, falar/ouvir e ler/escrever sobre suas experiências formadoras, descortinar possibilidades de/na formação, por meio do vivido, organiza as ideias e potencializa a reconstrução de sua vivência pessoal e profissional de forma autorreflexiva como suporte para a compreensão de sua itinerância vivida. Assim como provoca uma reflexão acerca de si mesmo e dos outros, caracterizando-se como boa estratégia de formação.

A experiência com as escritas na escola trouxe a compreensão que não é possível olhar a escola com um olhar solitário, é preciso olhar a escola através de múltiplos olhares, de infinitas vozes, de diferentes gestos. O cotidiano da escola é repleto de histórias de vidas que se constituem na interação com o outro, e essa constituição é possível quando o sujeito não é instituído e determinado, quando a sua trajetória de vida the possibilita escolhas, quando os seus saberes são valorizados e não descartados, quando são vistos e ouvidos como sujeitos potenciais.

Possibilitar às professoras a prática da escrita foi reconhecê-las como sujeitos narradores, aqueles que narraram sua vida e suas ações sem se distanciar do cotidiano, de forma singular e artesanal, possibilitando o intercâmbio das experiências e das aprendizagens extraídas de vivências particulares e/ou coletivas (BENJAMIN, 1994).

\section{Pesquisar COM e NA escola: deslocar-se no lugar do acontecimento}

Ao lançar-se com e na pesquisa, a professora coordenadora pôs-se diante de um grande desafio: enxergar para além do que está posto e determinado, e olhar para as brechas, 
para os pormenores e para as desimportâncias, e assim mostrar um olhar investigador ao ler as escritas das educadoras, "baseado na apreensão de detalhes marginais e irrelevantes enquanto chaves reveladoras" (GINZBURG, 2008, p. 96). Dessa forma, os olhares dela miraram para as palavras que revelavam afazeres, marcados por diferentes desafios, e como consequência disso foi possível organizar os espaços de formação na escola, conforme as demandas que essas escritas apresentavam e, assim, auxiliar as professoras a desenvolverem um trabalho que fosse significativo tanto para elas, quanto para as crianças.

Essas escritas oportunizaram muitos deslocamentos, entre eles o excedente de visão (BAKHTIN, 2003), percebidos em dois momentos: quando as escritas das educadoras apresentaram algo sobre a professora coordenadora, e quando a pesquisadora (professora coordenadora) arriscou-se a dar acabamento à sua pesquisa, pois pesquisar a própria prática exige $\mathrm{o}$ afastamento de si próprio, colocar-se à margem de si mesmo para se compreender e se completar.

Nesse movimento de escrita, projetaram-se na professora coordenadora diferentes formas de conduzir o seu trabalho, porém as escritas e as relações estabelecidas com as professoras apontaram os caminhos pelos quais ela deveria trilhar. Foi um deslocamento difícil para a professora coordenadora, que enquanto pesquisadora da sua própria prática teve que antepor-se a si mesma, pois a sua existência presente já não é a mesma existência do passado, algo revelado nas suas memórias.

Para Bakhtin (2003), constituir-se pelo excedente de visão é a "compreensão como visão do sentido, não uma visão fenomênica e sim uma visão do sentido vivo da vivência na expressão, uma visão do fenômeno internamente compreendido, por assim dizer, autocompreendido" (p. 396, grifo do autor). Sentido como alteridade, a descoberta da presença do outro por meio das palavras, do olhar, da contemplação junto à elaboração criadora, reflexiva e expansiva.

Tanto as professoras quanto a professora coordenadora estiveram diante de desafios cotidianos que foram revelados nas suas escritas, e tal interlocução permitiu, para além do acolhimento e do sentimento de pertencimento, a superação de momentos conflituosos na escola, a partir do respaldo da professora coordenadora que se atentou para a organização do trabalho de acordo com a realidade do cotidiano e do empenho das professoras, que acompanharam os passos da professora coordenadora estando ao seu lado em busca de objetivos comuns e necessários a uma prática pedagógica que priorizasse as crianças.

A interlocução entre as professoras e a professora coordenadora possibilitou uma relação mais íntima, sincera e transparente, que, segundo Giddens (1993), permite o abrir-se para o outro considerando seus limites pessoais, ao exigir a sensibilidade, o tato e o respeito aos pensamentos particulares e ao implicar a democratização do domínio interpessoal, compatível com a democracia na esfera pública. Assim, é relevante a leitura que o autor faz acerca de como realmente nos tornamos íntimos uns dos outros, uma intimidade que está relacionada às escolhas, à satisfação, à liberdade, ao equilíbrio, à mutualidade, ao compromisso, à negociação e ao compartilhamento das vontades e dos sentimentos.

Aprendeu-se, por intermédio dessa experiência e da interlocução com Tardif (2010) e Geraldi (2004), que a escola não é somente um lugar de aplicação de saberes produzidos 80 Comunicações | Piracicaba | v. 24 | $\mid$ n. 3 | p. 67-83 | setembro-dezembro 2017 
por outros, mas é espaço de produção, transformação e mobilização de saberes, que lhe são próprios. Uma experiência formativa que propõe pensar a escola como produção de conhecimentos e resultado de novas articulações entre os saberes e conhecimentos disponíveis. Mas, para isso, é preciso que os educadores falem sobre o que sabem e fazem. A escola vista como espaço coletivo para trabalhar, trocar, aprender e investigar a própria prática profissional, possibilitando que os sujeitos se constituam enquanto sujeitos responsivos, que ocupam um lugar singular, o lugar da sua assinatura, assinatura como aquilo "que me torna responsável capaz de responder pelo lugar que ocupo num dado momento, num dado contexto" (AMORIM, 2003, p. 14-15).

Dessa forma, a professora coordenadora teve que mobilizar os espaços de formação, de modo que as educadoras também se responsabilizassem por seu processo formativo, ou ainda que compreendessem a sua responsabilidade diante do desenvolvimento e da aprendizagem das crianças, e nesse contexto as práticas de escritas trouxeram grandes contribuições, ao sensibilizar as educadoras (professoras e professora coordenadora) a olharem para si mesmas, para a escola, para as crianças, para o ordinário da vida, que é extraordinário.

\section{REFERÊNCIAS}

AMORIM, Marília. A contribuição de Mikhail Bakhtin: a tripla articulação ética, estética e epistemológica. In: FREITAS; SOUZA; KRAMER. Ciências humanas e pesquisa: leituras de Mikhail Bakhtin. São Paulo: Cortez, 2003, p. 11-25.

ANDRÉ, Marli. O cotidiano escolar: um campo de estudo. In: PLACCO, Vera Maria Nigro de Souza; ALMEIDA, Laurinda Ramalho. O coordenador pedagógico e o cotidiano da escola, 8. ed. São Paulo: Edições Loyola, 2010, p. 9-19.

BAKHTIN, Mikhail. Estética da Criação Verbal. São Paulo: Martins Fontes, 2003.

. Marxismo e filosofia da linguagem: problemas fundamentais de método sociológico da linguagem. São Paulo: Hucitec, 2011.

BARROS, Manoel de. Memórias Inventadas: as infâncias de Manoel de Barros. São Paulo: Editora Planeta do Brasil, 2008.

BENJAMIN, Walter. Magia e técnica, arte e política: ensaios sobre literatura e história da cultura. São Paulo: Brasiliense, 1994.

CERTEAU, Michael. A invenção do cotidiano: artes de fazer. Petrópolis, RJ: Vozes, 1994.

CHALUH, Laura N. Formação e alteridade: pesquisa na e com a escola. Tese (doutorado) Universidade Estadual de Campinas. Faculdade de Educação. Campinas, SP, 2008.

. A simultaneidade de lugares da pesquisadora na escola: um movimento caleidoscópio. Revista Teias, v. 12, n. 25, p. 238-255, 2011.

COLLARES, Cecília A. L.; MOYSÉS, Maria A. A.; GERALDI, João W. Educação continuada: a política da descontinuidade. Educação \& Sociedade, ano XX, n. 68, dez. 1999. 
CUNHA, Renata C. O. B.; PRADO, Guilherme do Val T. Formação centrada na escola, desenvolvimento pessoal e profissional de professores. Revista de Educação. PUC-Campinas, Faculdade de Educação, n. 28, p. 101-111, jan./jun. 2010.

DUTRA, Elza. A narrativa como uma técnica de pesquisa fenomenológica. Revista Estudos de Psicologia, 7 (2), 371-378. Universidade Federal do Rio Grande do Norte, 2002.

FONTANA, Roseli A. C. Como nos tornamos professoras? Belo Horizonte: Autêntica, 2003.

FREINET, Célestin. A educação do trabalho. São Paulo: Martins Fontes, 1998.

FREIRE, Paulo. Pedagogia da autonomia: saberes necessários à prática educativa. São Paulo: Paz e Terra, 2011.

FREITAS, Maria T. A. A perspectiva sócio-histórica: uma visão humana na construção do conhecimento. In: FREITAS; SOUZA; KRAMER. Ciências humanas e pesquisa: leituras de Mikhail Bakhtin. São Paulo: Cortez, 2003, p. 26-38.

FURLANETTO, Ecleide. O Papel do Coordenador Pedagógico na Formação Continuada do Professor: Dimensões Interdisciplinares e Simbólicas. In: QUELUZ, Ana Gracinda (Org.) Interdisciplinaridade: formação de profissionais da educação. São Paulo: Pioneira, 2000, p. 85-101.

GERALDI. João W. A aula como acontecimento. Theoria Poiesis Práxis. Portugal: Universidade de Aveiro, mai. 2004.

. A aula como acontecimento. São Carlos: Pedro\&João Editores, 2010.

GIDDENS, Anthony. A transformação da intimidade: sexualidade, amor \& erotismo nas sociedades modernas. São Paulo: Editora da Universidade Estadual Paulista, 1993.

GINZBURG, Carlo. Sinais. Raízes de um paradigma indiciário. In: . Mitos, emblemas, sinais. São Paulo: Companhia das Letras, 1989, p. 143-179.

. Chaves do Mistério: Morelli, Freud e Sherlock Holmes. In: ECO, Umberto; SEBEOK, Thomas A. O signo de três. São Paulo: Perspectiva, 2008.

JOBIM e SOUZA; Solange; ALBUQUERQUE, Elaine D. P. e. A pesquisa em ciências humanas: uma leitura bakhtiniana. Bakhtiniana. São Paulo, v. 7, n. 2, p. 109-122, jul./dez. 2012.

LARROSA, Jorge. Notas sobre a experiência e o saber da experiência. Revista Brasileira de Educação. ANPED. Campinas: Autores Associados, 2002, n. 19.

LIMA, Maria Emília C. C.; GERALDI, Corinta M. G.; GERALDI, João W. O trabalho com as narrativas na investigação em educação. Educação em Revista, v. 31, n. 1, p. 17-44, jan./mar. 2015.

NÓVOA, Antonio. O regresso dos professores. Conferência: Desenvolvimento profissional de professores para a qualidade e para equidade da aprendizagem ao longo da vida. Lisboa, Parque das Nações, set. 2011. 
PIERINI, Adriana S.; SADALLA, Ana Maria. F. A. Laços se formam a partir de nós - coletivos que reconfiguram o trabalho de orientação pedagógica na escola pública. In: PLAC$\mathrm{CO}$, Vera; ALMEIDA, Laurinda (Org.). O coordenador pedagógico e os desafios da educação. SP: Loyola, 2008.

PINTO, Keila S. Desdobramentos das escritas de educadoras nos espaços de formação na escola. Dissertação de Mestrado em Educação. Instituto de Biociências, Universidade Estadual Paulista, Rio Claro, 2016.

PRADO; Guilherme do Val T.; CUNHA, Renata C. O. B. Aprender com a experiência: a produção de quais saberes? Educação: Porto Alegre, RS, ano XXIX, n. 1 (58), p. 107-122, jan./abr. 2006.

SANTOS. Boaventura de S. Um discurso sobre as ciências. Porto: Edições Afrontamento, 2010.

SERPA. Andréa. Pesquisa com o cotidiano: desafios e perspectivas. In: LINHARES, Célia; GARCIA, Regina L.; Corrêa, Carlos H. A. (Orgs.). Cotidiano e formação de professores, 2011, p. 39-60.

SOUZA, Elizeu C. O conhecimento de si: estágios e narrativas de formação de professores. Rio de Janeiro: DP\&A, Salvador: BA, UNEB, 2006.

. Memórias e trajetórias de escolarização: abordagem experiencial e formação de professores para as séries iniciais do ensino fundamental. ANPED, GT: Educação Fundamental /n. 13, 2004. Disponível em: http://27reuniao.anped.org.br/gt13/t133.pdf, acesso em 5 de setembro de 2015.

TARDIF, Maurice. Saberes docentes e formação profissional. Petrópolis, RJ: Vozes, 2010.

\section{DADOS DAS AUTORAS}

\section{KEILA SANTOS PINTO}

Mestre em Educação pelo Programa de Pós-graduação em Educação do Instituto de Biociências da Universidade Estadual Paulista. Professora coordenadora em uma Escola Municipal de Rio Claro. Rio Claro/SP - Brasil. keila_sp22@yahoo.com.br

\section{LAURA NOEMI CHALUH}

Doutora em Educação pela Universidade Estadual de Campinas. Professora do Departamento de Educação e do Programa de Pós-Graduação em Educação da Universidade Estadual Paulista. Rio Claro/SP - Brasil. lchaluh@rc.unesp.br

Submetido em: 14-12-2016

Aceito em: 19-9-2017 